\title{
Revista de Lenguas para Fines Específicos
}

https://ojsspdc.ulpgc.es/ojs/index.php/LFE/index

\section{Modal verbs in the abstract genre in the field of tourism}

\section{Francisco J. Álvarez-Gil ${ }^{1}$, Elena Domínguez-Morales}

Universidad de Las Palmas de Gran Canaria

Departamento de Filología Moderna, Calle Pérez del Toro, 1 - 35004, Las Palmas de Gran Canaria (Gran Canaria), Spain

\section{Article history}

Paper received: 26062018 Paper received in revised form and accepted for publication: 16102018

\section{Keywords}

Modal verbs, modality, mitigation, English, tourism

\author{
ABSTRACT
}

This paper looks into the use of modal verbs in a corpus of abstracts excerpted from scientific papers in the field of tourism. These texts have been written by specialists in tourism studies. Our study will show the way in which modality is used to show the authors' intention as to the contents of their texts. The pragmatic implications of modal uses will be highlighted bearing in mind the purposes of the abstract genre within the academic paper. The methodology of study is corpus linguistics, and the framework of analysis includes the works of Palmer (1979; Palmer, 1986) and Collins (2009), among others. This paper is part of a larger research on modal verbs in touristic scientific papers.

\section{Introduction}

This paper studies the use of modal verbs and their meanings in a corpus of abstracts excerpted from scientific papers in tourism studies. The study of modality in the scientific domain and specialised texts is not new, as put forward in the works of Giltrow (2005), Hyland (1994), Cheng and Cheng (2014), and Biel (2014), among others. To our knowledge, the study of modality in abstracts in the register of tourism has not been the focus of earlier studies. In this paper, we concentrate on these verb forms in order to unveil the authors's intentions, and whether there are preferences as to the type of modal meanings found in abstracts.

Our framework of analysis considers the notion of stance (Hyland, 2005; Kärkkäinen, 2006), as modal verbs frequently indicate some degrees of commitment and/or authority towards the contents expressed. This use of modal verbs indicates, thus, the attitude of the authors, and that means the way in which the authors want to convey information in scientific writing. Truth be told, some of these modals are used to meet the requirements 
of academic courtesy (Alonso-Almeida, 2014; Alonso-Almeida \& Cruz-García, 2011) rather than any other pragmatic goal, as we shall see later on in this paper. The analysis of modal verbs in writing (Cf. Auwera \& Plungian, 1998; Biber, 2004; Collins, 2009; Depraetere \& Reed, 2008; Egan, Hawthorne, \& Weatherson, 2005; Nuyts, 2001) and, particularly, in specialised and scientific writing will also benefit from earlier literature on the topic (Cf. Giltrow, 2005; Kranich, 2009; Yang, Zheng, \& Ge, 2015).

The structure of the paper is, as follows. In section 2, the framework of analysis is presented. This is followed by a description of the method and a description of the corpus. The results obtained from an inquiry of the corpus are given and discussed in section 4. The last section offers the conclusions drawn from the present research.

\section{Modality and modal verbs}

The concept of modality is not a straightforward one, as authors do not seem to fully agree as to what this notion should include in language. Palmer $(1986$, p. 2) states that modality is certainly a vague term, and concedes that modality indeed represents the author's stance, since it reflects an attitude and an opinion. That is the case in the following examples:

(1) The winner may be within these five.

(2) Probably, the winner is one within these five.

In these two examples, opinion is encoded in the use of the verb form may in the case of (1). This verb form suggests that the event described is likely to happen, and so epistemic probability is indicated. In the same way, the adverbial probably in (2) has a similar function of designating probability that the event given in the propositional content is likely to take place in the future (see Álvarez-Gil, 2019 for more information on adverbs and adverbials). This use of adverbials pairs with other linguistic expressions, such as lexical items and syntactic matrices, to mean modality. One example of a matrix matching the meaning in (1) and (2) is given in (3):

(3) It is probable/likely that the winner is within these five.

This idea of modality is central to our study, and so modality is to be found under the scope of what is known as stance, as already pointed out. Alonso-Almeida (2015a, p. 2) states that the term stance

indeed refers to different phenomena in language, and so it is generally the umbrella term for notions, such as epistemic stance (Finegan, 1989), commitment (Caffi, 1999, 2007; Del Lungo Camiciotti, 2008), mitigation (Alonso-Almeida, 2015b; Martín-Martín, 2008), reinforcement or strengthening (Brown, 2011), intensification (Gonzalez, 2015), authority, involvement and hedging (Ken Hyland, 1998, 2005), assessment (Goodwin, 2006), modality and evidentiality (M. L. Carrió-Pastor, 2012; Chafe, 1986; Fairclough, 2004; Goodwin, 2006; Marín Arrese, 2009; Frank R. Palmer, 1986; Pic \& Furmaniak, 2012), affect (Martin, 2000; Martin \& White, 2005), and vagueness in language (Cutting, 2007).

With this in mind, our perspective of modality includes an evaluative dimension, and therefore, modality is used with an intention to qualify how a particular event may have occurred, may occur, is due to occur, and is expected to occur, among other possibilities. In many ways, modality, and especially epistemic modality, is subjective (Alonso-Almeida, 2015a), as also put out in Hyland (1997, 1994, 2002) and Carrió-Pastor (CarrióPastor, 2014, 2016; María Luisa Carrió-Pastor \& Calderón, 2015), among others. 


\subsection{Modality types}

Modality is frequently realised by means of modal verbs (Collins, 2009), and these are the ones we focus on in the present study. The modality types followed in this paper are that in Palmer (1986), and so we meet the threefold division of modality into (a) epistemic modality, (b) deontic modality, and (c) dynamic modality. Epistemic modality is "concerned with matters of knowledge or belief on which basis speakers express their judgements about state of affairs, events or actions" (Hoye, 2008, p. 42), and "[...] applies to assertions and indicates the extent to which the speaker is committed to the truth of the proposition" (Bybee, Perkins, \& Pagliuca, 1994, p. 179). This makes clear that this type of modality is frequently associated with the idea of truth. Deontic modals are related to the "[...] necessity of acts in terms of which the speaker gives permission or lays an obligation for the performance of actions at some time in the future" (Hoye 1997: 43). Dynamic modality is a more complex term, as it is frequently confused with epistemic modality, as both types of modality refer to what is possible. Alonso-Almeida and Carrió-Pastor (2017, p. 279) defines dynamic modality in the following terms:

In dynamic modality, conditions are internal, and it involves senses of willingness and ability on the part of the speaker or writer. Dynamic modality refers to the potentiality of the speaker to develop an action, whether this potentiality be internally or externally motivated, as the enabling circumstances are external or internal.

In what follows, we revise the use of modal verbs and modality types in abstracts in the field of tourism in order to assess the functions these modals fulfil, and which modality type appears to be more frequent in this genre.

\section{Corpus and method}

In this section, we explain the corpus selected for the study of modal verbs along with our method of inquiry.

\subsection{Corpus design. The abstract on tourism}

The corpus represents a controlled sample of thirty specialised abstracts on tourism written in English. The criteria for selection included only two requisites: (1) the text should be written in English, and (2) the text should be included in a leading journal in the field. The fact that language is placed as the one requisite regardless the place of birth of the authors may be questioned and certainly defied by many. Our view, however, is that neither the place of birth or the anglosaxon surname may lead us to think of an anglosaxon upbringing and education, and therefore, we preferred to analyse language without taking an English background of the authors for granted. A Dr. Smith may have obtained his surname from his ancestors, but he may live in Croatia since their grandgrandparents arrived more than a hundred years ago, and then his contact with the English language is via academic learning. The small number of abstracts selected in this sample followed from our intention of analysing in detail the contexts in which modals appear in order to unveil pragmatic and/or discourse functions.

The abstract on tourism does not seem to represent a well-established genre, and so informative stages depend greatly on what we suppose is the tradition of each journal or the intuition of the writers. There are, however, abstracts (as shown in Domínguez Morales, n.d.) in this field of knowledge, and so some abstracts, as the one given below, present a much formalised structure given in the journal's set of guidelines for authors. One case in point might be the following (blue font in example is ours): 
competitiveadvantage in the housekeeping (HK) department of five-star hotels in Dubai and consider how the nature of the industry in the region provides particular challenges.

Design/methodology/approach - An initial White Paper produced by Amadeus served as the stimulus to conduct a preliminary literature review of innovation in the field of hospitality. The application of innovation was then considered via a content analysis of web sites in Dubai to identify potential candidates for interview. Semi-structured interviews were conducted with Senior Housekeeping Executives in two internationally recognized chain hotels in Dubai to better understand whether there is a need for innovation, what types of innovation are important within these HK departments and understand the potential challenges confronting senior managers in fostering innovative practices.

Findings - The key results of this study provide interesting insights into the problems of developing and managing innovation within HK operations, highlighting the issues that exist as potential barriers to innovation in terms of the organizational culture and the ownership structure within the industry in Dubai. The research also highlights the fact that much of the innovation introduced within the HK department is focused on utilization of technology and is very much "output"-orientated in terms of improving customer service and creating operational efficiencies.

Research limitations/implications - The paper profiles the potential problems confronting the HK department when it comes to identifying and adopting innovation. The paper also highlights the everchanging nature of the organizational culture and the ownership structure in the five-star hotel industry in Dubai as a critical influence in terms of the perceived importance of innovation as a success factor for the future.

Originality/value - The study is the first in a series of research papers that explores the relationship between key stakeholders in the hospitality industry in Dubai as the customer demand alters and they try to identify and implement innovative ideas and concepts that provide return on investment, increased customer satisfaction, sustainability and competitive advantage. It is the first paper that identifies the context and the current internal and external environments and the drivers within the industry in Dubai (five-star) hotels with a particular focus on 2020. This is within an industry that is showing evidence of change management within the customization of the hotel build and specification, and within the adaption of IT, but is looking for innovation within the application of ideas into industry processes. ${ }^{2}$

As shown in this example, information is given in chunks presenting aspects concerning objectives and achievements along with matters of potentialities of the paper in terms of contributions to the field. These stages constitute the generic structure of this abstract (Figueiredo, 2010; Martin, 1997).

\subsection{Method. Corpus inquiry}

The method of study is corpus linguistics. The texts have been retrieved in pdf format and keyed as plain texts and stored as txt files for use with corpus tools. In this particular case, the directory containing our selection of abstracts has been processed using CasualConc software suite by Yasu Imao. ${ }^{3}$ The corpus has been interrogated to retrieve examples containing the forms can, could, may, might, shall, should, will, would, ought to, have to and

2 Angela Anthonisz, (2014) "Assessing the future of housekeeping operations in Dubai's five-star hotel industry - room for innovation?", Worldwide Hospitality and Tourism Themes, Vol. 6 Issue: 4, pp.352-361, https://doi.org/10.1108/WHATT-01-20140005

3 http://casualconc.blogspot.com. 
has to. The concordances retrieved are analysed with special attention to the context in order to detect the type of modality these forms convey. The files in the corpus are labelled using the word tourism and a number.

\section{Results and discussion}

The following graph reveals the modal meanings found in the abstracts under analysis:

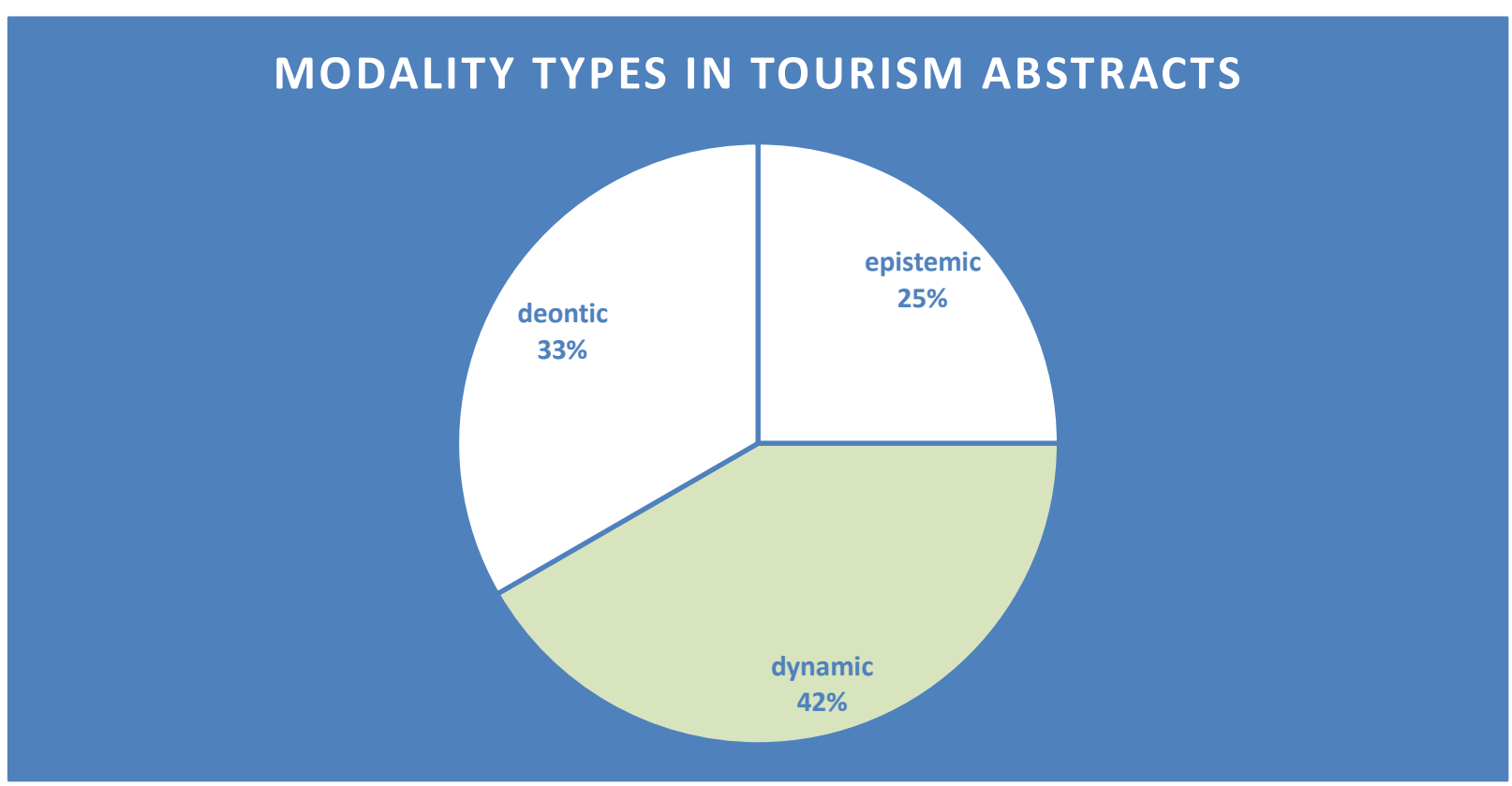

Figure 1. Modality types in tourism abstracts.

Figures indicate that dynamic modality is the most common type of modality used in the abstracts and this is followed by deontic modality. Epistemic modality is found to appear only in a $25 \%$ of the cases. This fact is certainly surprising, as one would expect some kind of authorial hesitancy and caution at this point of the article in order to attenuate propositional content.

The following figure gives the distribution of modals according to meaning: 


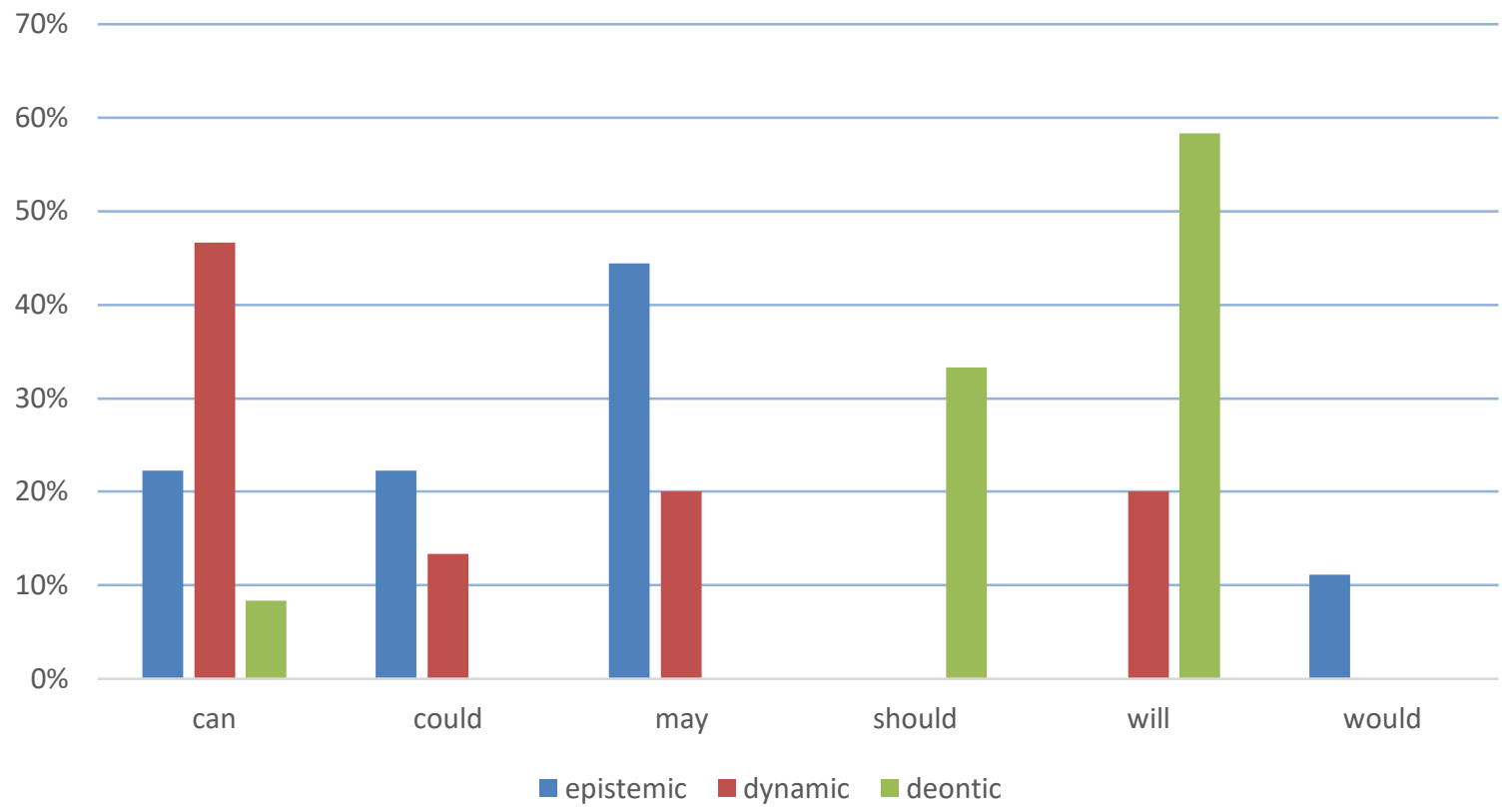

Figure 2. Distribution of modal verbs according to modality type in tourism abstracts.

Figure 2 shows that deontic will, dynamic can and epistemic may are the most frequent forms in abstracts, and this figure also evinces that can, could and may are used to indicate epistemic and dynamic probability indistintively in the corpus, although may seems to be more in association with epistemic probability and can with dynamic probability.

\subsection{Epistemic modality}

Epistemic modals include the forms may, can, could, and would. The verb may is the most common form. One example is given in (1):

(1) Changing the climate and weather conditions of any destination may affect the tourists' comfort and travel decisions, and due to the changing demand pattern and tourist flows, tourism businesses and host communities suffer. Cancellation of any trip due to bad weather causes dissatisfaction and those affected may avoid visiting the destination again (tourism-28).

In this example, the form may serves as a hedge with a clear mitigating function, as the authors seek to provide information that is thought to happen in the future. In this text, the authors indicate that there is a probability that aspects, such as the change of climate conditions, have a consequence in the tourists' travel decisions. It could also be the case that may is used here as a negative politeness strategy to avoid imposition on their readers (Alonso-Almeida, 2014, 2015b; Carrió-Pastor, 2016). A similar function is fulfilled by could in (2), below:

(2) Sharing conservation revenue with communities surrounding parks could demonstrate the link between ecotourism and local communities' economic development, promote a positive view of land restitution involving parks, help address skewed distribution of income in the vicinity of parks and act as an incentive for local communities to participate in conservation even more (tourism-13).

In this example, the use of could indicates that there is a tentative probability that sharing conservation revenue with the local communities is likely to produce benefits for the industry and for each specific community. The 
modal verb can in (3) and (4) behaves in a similar way:

(3) The user-generated content these consumers post on social media Web sites influences those who read their posts or view aggregate ratings of multiple reviews about a product. It can move the reader to either purchase or not purchase the products. Social media is an important source of consumer information and can create new customers (tourism-27)

(4) The objective of this study is to quantify the degree to which an increasing number of non-stop flights can promote tourist arrivals at long-haul destinations (tourism-1).

The difference between epistemic and dynamic can is not always easy. In these instances, can seems to be halfway between what is probable and what is potential, but thorough contextual analysis suggests that the authors seem to indicate some degree of likelihood that the reader is willing to buy the products or otherwise. This particular example could be also indicating that the content posted on websites has the potentiality to trigger certain behaviour on customers in the same way the second use of can in can create in (3) indicates the capacity of social media to create new customers. The form can in (4) clearly indicates likely probability, and so can appears to have a downtoning effect.

\subsection{Deontic modality}

Deontic modality clearly shows the stance of the authors towards the information presented. This type of modality is expressed by can, should and, especially, will. The use of should in (5), below, reflects the authors' view of how things are estimated to be in the light of the evidence put forward in the research conducted. The strong effects this modal may bring in terms of obligation is somehow lessened by the use of the string be possible to mean tentativeness.

(5) The results of the research help to provide a better understanding of the conditions needed to develop and manage sustainable tourism in post-conflict environments. In so doing, it should be possible to make better policy decisions, with particular reference to social and urban interventions on planning, design and entrepreneurship (tourism-30).

The form will, however, reflects the authors' convinction in relation to the events described, as in (6) and (7):

(6) The identification of trends that are affecting social media and will continue to affect social media in the future will provide immediate benefits to practitioners and researchers with a stream of research ideas (tourism-27).

(7) There is a need for detailed and comprehensive legislation protecting the rights and needs of disabled tourists, particularly in view of Dubai's successful bid to host Expo 2020. This need will, no doubt, be fulfilled in light of the recent announcement that Dubai will enact its own disability law intended to make the emirate fully accessible to persons with disabilities (tourism-24).

This sense of conviction is particularly noticeable in (7) where the author deploys the evidential expression no doubt given parenthetically to make manifest that some kind of evidence is owned to reach the particular conclusion introduced in the proposition framed by will.

\subsection{Dynamic modality}

As already pointed out, dynamic modality is the most frequent modal type in the abstracts analysed. It happens that this type of modality is very adequate in scientific writing, as Alonso-Almeida (2015c, p. 404) states that "dynamic modality is used even when the context implies assurance". This assurance relies, Alonso-Almeida 
(Alonso-Almeida, 2015c) on the capacities of a particular object to achieve a particular function, and so the use of dynamic modality conveys an expression of factual truth, as in (8), below:

(8) The article will be of value to practitioners, researchers, policy makers and other stakeholders involved in the food industry (tourism-19).

In this example, the use of will makes clear that the authors are aware of the contribution the article represents for the food industry, and they therefore identify this as factual truth by using dynamic will. The forms may and can in the following examples also indicate dynamic possibility, and so the authors acknowledge the potential of city policymakers in (9) and social transformation in (10) below to trigger the events described in their propositional contents.

(9) In this paper, the authors apply triangular fuzzy numbers (TFNs) to a survey of tourists who visited La Laguna in 2010. The results show that VEQ is highly affected by the transport mode used in the visit and, therefore, city policymakers may extract important implications for future visitors (tourism9).

(10) The purpose of this study is to explore how social transformation can lead to urban transformation, forming the basis for sustainable, post-conflict tourism (tourism-30).

\section{Conclusion}

This article shows ongoing research in the study of modals in scientific papers in the domain of tourism. The results have evinced that dynamic modals occur more often than epistemic and deontic modals in abstracts. Alonso-Almeida (Alonso-Almeida, 2015c) in his study on scientific abstracts in the field of computing admits that "[m]odals in abstracts are primarily dynamic since there is a clear authorial tendency to show factuality rather than speculation at this stage of the scientific article". The use of deontic modals in this genre is also worth noting. Obligation in the sense of necessary outcome of a particular process is expressed by using should and will, preferably. This use of the modals also account for the idea of factual truth, as evidences are there that lead authors to held this particular stance.

Epistemic modality is also found in these texts, but this type of modality does not seem to be of the authors' preference at this point of the scientific article. When this type of modality shows, its use appears to be indicative of authorial modesty, or even a desire to avoid imposition, rather than to show speculation or the authors' hesitancy to claim a particular proposition.

Future research includes a deep analysis of this genre, but also of the article genre as a whole or according to each generic stage to detect variation and the pragmatic functions associated. This necessarily involves a genre and register analysis of texts.

\section{Acknowledgements}

This paper is written within the framework of research grant FFI2016-75599-P, Ministerio de Economía y Competitividad (MINECO). 


\section{About the author}

Francisco José Álvarez-Gil, PhD, is a lecturer of English language and linguistics in the Department of Modern Philology, Translation and Interpreting, Universidad de Las Palmas de Gran Canaria. He also teaches French and English at secondary level in Gran Canaria. He has written his doctoral on adverbs as stancetaking devices in the Coruña Corpus of English History Texts (1700-1900). He has delivered talks on some linguistic aspects of Modern English scientific writing in international conferences of the field. He has been a visiting scholar in some reputed Universities with leading departments in English for Specific Purposes (ESP). His research interests primarily concern the analysis of specialised English from a synchronic and diachronic perspective, corpus linguistics, and language pedagogy at tertiary level.

María Elena Domínguez-Morales is a lecturer of English for Specific Purposes in the Department of Modern Philology, Translation and Interpreting, Universidad de Las Palmas de Gran Canaria. She also teaches English at secondary level. She is now writing her $\mathrm{PhD}$ dissertation on the language of scientific texts in the field of tourism with a special focus on modal verbs. She has participated in language conferences dealing with English for specialised purposes.

\section{References}

Alonso-Almeida, F. (2014). Evidential and epistemic devices in English and Spanish medical, computing and legal scientific abstracts: A contrastive study. In M. Bondi \& R. Lorés Sanz (Eds.), Abstracts in Academic Discourse. Linguistic Insights (pp. 21-42). Bern/ New York: Peter Lang.

Alonso-Almeida, F. (2015a). Introduction to stance language. Research in Corpus Linguistics, 5(3), 1-5.

Alonso-Almeida, F. (2015b). On the mitigating function of modality and evidentiality. Evidence from English and Spanish medical research papers. Intercultural Pragmatics. https://doi.org/10.1515/ip-2015-0002

Alonso-Almeida, F. (2015c). Sentential epistemic and evidential devices in Spanish and English texts on computing. In J. R. Zamorano-Mansilla, C. Maíz, E. Domínguez, \& M. V. M. de la Rosa (Eds.), Thinking Modally: English and Contrastive Studies on Modality (pp. 383-408). Newcastle upon Tyne: Cambridge Scholars Publishing.

Alonso-Almeida, F., \& Carrió-Pastor, M. L. (2017). Variation and Function of Modals in Linguistics and Engineering Research Papers in English. In J. I. Marín-Arrese, J. Lavid-López, M. Carretero, E. D. Martín de la Romero, M. V. Rosa, \& M. Pérez Blanco (Eds.), Evidentiality and Modality in European Languages. Discourse- pragmatic perspectives (pp. 277-311). Bern, Berlin, Bruxelles, Frankfurt am Main, New York, Oxford, Wien: Peter Lang.

Alonso-Almeida, F., \& Cruz-García, L. (2011). The value of may as an evidential and epistemic marker in English medical abstracts. Studia Anglica Posnaniensia, 46(3). https://doi.org/10.2478/v10121-010-0004-7

Álvarez-Gil, F. J. (2019). Adverbs in -ly in late Modern English. Evidence from the Coruña Corpus of History English Texts. Serie: Estudios de Lingüística Aplicada, Vol. 4. Valencia: Editorial UPV.

Auwera, J. Van der, \& Plungian, V. (1998). Modality's semantic map. Linguistic Typology, 2(1994), 79-124.

Biber, D. (2004). Modal use across registers and time. In A. L. Curzan \& K. Emmons (Eds.), Studies in the History of the English Language II: Unfolding Conversations; [second Biennial Meeting of the Studies in the History of the English Language Conference (abbreviated SHEL-2), was Held at the University of Washington in Seattle in March of 20 (pp. 189-216). Berlin: Walter de Gruyter.

Biel, Ł. (2014). The textual fit of translated EU law: A corpus-based study of deontic modality. Translator. 
https://doi.org/10.1080/13556509.2014.909675

Brown, L. (2011). Korean Honorifics and Politeness in Second Language Learning (Vol. 206). Amsterdam: John Benjamins Publishing Company. https://doi.org/10.1075/pbns.206

Bybee, J. L., Perkins, R. D., \& Pagliuca, W. (1994). The evolution of grammar: tense, aspect, and modality in the languages of the world. Chicago (III.): University of Chicago press.

Caffi, C. (1999). On mitigation. Journal of Pragmatics, 31(7), 881-909. https://doi.org/10.1016/S0378-2166(98)00098-8

Carrió-Pastor, M. L. (2012). A contrastive analysis of epistemic modality in scientific English. Revista de Lenguas Para Fines Específicos, 18, 115-132.

Carrió-Pastor, M. L. (2014). Cross-cultural variation in the use of modal verbs in academic English. SKY Journal of Linguistics.

Carrió-Pastor, M. L. (2016). Mitigation of claims in medical research papers: A comparative study of English- and Spanish-language writers. Communication and Medicine. https://doi.org/10.1558/cam.28424

Carrió-Pastor, M. L., \& Calderón, R. M. (2015). A Contrastive Analysis of Metadiscourse Features in Business e-mails Written by Non-native Speakers of English. Procedia - Social and Behavioral Sciences. https://doi.org/10.1016/j.sbspro.2015.02.055

Chafe, W. (1986). Evidentiality in English conversation and academic writing. In W. Chafe \& J. Nichols (Eds.), Evidentiality: The Linguistic Coding of Epistemology (pp. 261-272). Norwood: Ablex.

Cheng, W., \& Cheng, L. (2014). Epistemic modality in court judgments: A corpus-driven comparison of civil cases in Hong Kong and Scotland. English for Specific Purposes. https://doi.org/10.1016/j.esp.2013.07.006

Collins, P. (2009). Modals and quasi-modals in English / Peter Collins. Amsterdam: Rodopi.

Cutting, J. (2007). Introduction to Vague language explored. In Vague Language Explored (pp. 3-17). New York: Palgrave Macmillan.

Del Lungo Camiciotti, G. (2008). Two polite speech acts from a diachronic perspective: Aspects of the realisation of requesting and undertaking commitments in the nineteenth-century commercial community. In A. H. Jucker \& I. Taavitsainen (Eds.) (pp. 115-131). Amsterdam/ New York: John Benjamins Publishing. https://doi.org/10.1075/pbns.176.07del

Depraetere, I., \& Reed, S. (2008). Mood and Modality in English. In The Handbook of English Linguistics (pp. 269-290). Malden, MA, USA: Blackwell Publishing. https://doi.org/10.1002/9780470753002.ch12

Domínguez Morales, E. (n.d.). The abstract genre in scientific articles on tourism. In F. J. Álvarez-Gil \& M. Bondi (Eds.).

Egan, A., Hawthorne, J., \& Weatherson, B. (2005). Epistemic modals in context. In G. Preyer \& G. Peter (Eds.), Contextualism in philosophy (pp. 131-170). Oxford: Oxford University Press. https://doi.org/9780199267408 (hbk) 9780199267415 (pbk.)

Fairclough, N. L. (2004). Analysing Discourse: Textual Analysis for Social Research. New York.

Figueiredo, D. (2010). Context, register and genre: Implications for language education. Revista Signos, 43, 119-141. https://doi.org/10.4067/S0718-09342010000300008

Finegan, E. (1989). Styles of stance in English: Lexical and grammatical marking of evidentiality and affect. Text. https://doi.org/10.1515/text.1.1989.9.1.93

Giltrow, J. (2005). Modern Conscience: Modalities of Obligation in Research Genres. Text - Interdisciplinary Journal for the Study of Discourse, 25(2), 171-199. https://doi.org/10.1515/text.2005.25.2.171

Gonzalez, M. (2015). From truth-attesting to intensification: The grammaticalization of Spanish la verdad and Catalan la veritat. Discourse Studies, 17(2), 162-181. https://doi.org/10.1177/1461445614564519 
Goodwin, C. (2006). Retrospective and prospective orientation in the construction of argumentative moves. Text \& Talk - An Interdisciplinary Journal of Language, Discourse Communication Studies, 26(4-5), 443-461. https://doi.org/10.1515/TEXT.2006.018

Hoye, L. F. (2008). Evidentiality in discourse: A pragmatic and empirical account. In J. Romero-Trillo (Ed.), Pragmatics and Corpus Linguistics: A Mutualistic Entente (pp. 50-174). Berlin; New York: Mouton de Gruyter.

Hyland, K. (1994). Hedging in academic writing and EAF textbooks. English for Specific Purposes. https://doi.org/10.1016/0889-4906(94)90004-3

Hyland, K. (1997). Scientific claims and community values: articulating an academic culture. Language \& Communication, 17(1), 19-31.

Hyland, K. (1998). Hedging in Scientific Research Articles (Vol. 54). Amsterdam: John Benjamins Publishing Company. https://doi.org/10.1075/pbns.54

Hyland, K. (2002). Authority and invisibility: Authorial identity in academic writing. Journal of Pragmatics, 34, 10911112. Retrieved from http://www.sciencedirect.com/science/article/pii/S0378216602000358

Hyland, K. (2005). Stance and engagement: a model of interaction in academic discourse. Discourse Studies, 7(2), $173-$ 192. https://doi.org/10.1177/1461445605050365

Kärkkäinen, E. (2006). Stance taking in conversation: From subjectivity to intersubjectivity. Text \& Talk-An Interdisciplinary Journal of Language, ..., 6, 699-731.

Kranich, S. (2009). Epistemic Modality in English Popular Scientific Texts and Their German Translations. TransKom, 2(1), 26-41.

Marín Arrese, J. I. (2009). Effective vs. epistemic stance, and subjectivity/intersubjectivity in political discourse. A case study. In A. Tsangalidis \& R. Facchinetti (Eds.), Studies on English modality. In honour of Frank R. Palmer (pp. 2352). Bern/ New York: Peter Lang.

Martín-Martín, P. (2008). The Mitigation of Scientific Claims in Research Papers: A Comparitive Study. International Journal of English Studies. https://doi.org/10.6018/ijes/8/2/49201

Martin, J. R. (1997). Analysing genre: Functional parameters. In Genres and institutions: Social processes in the workplace and school (pp. 3-39). London: Cassell.

Martin, J. R. (2000). Beyond exchange: APPRAISAL systems in English. In S. Hunston \& G. Thompson (Eds.), Evaluation in text: authorial stance and the construction of discourse (pp. 142-175). Oxford: Oxford University Press.

Martin, J. R., \& White, P. R. R. (2005). The Language of Evaluation. London: Palgrave Macmillan UK. https://doi.org/10.1057/9780230511910

Nuyts, J. (2001). Subjectivity as an evidential dimension in epistemic modal expressions. Journal of Pragmatics, 33(3), 383-400. https://doi.org/10.1016/S0378-2166(00)00009-6

Palmer, F. R. (1979). Modality and the English modals (1st editio). London: Longman.

Palmer, F. R. (1986). Mood and modality. Cambridge textbooks in linguistics. Cambridge [Cambridgeshire] ; New York: Cambridge University Press.

Pic, E., \& Furmaniak, G. (2012). A study of epistemic modality in academic and popularised discourse: the case of possibility adverbs perhaps, maybe and possibly. Revista de Lenguas Para Fines Específicos, 18, 13-44.

Yang, A., Zheng, S. yuan, \& Ge, G. chun. (2015). Epistemic modality in English-medium medical research articles: A systemic functional perspective. English for Specific Purposes. https://doi.org/10.1016/j.esp.2014.10.005 